his property, his testamentary capacity being interfered with by the morbid fancies of his brain in regard to his relatives to whom, in his more sound judg. ment and when well in body, four times before he had left his property by will. In cross-examination he admitted that it was entirely a matter of degree whether irritability and suspicion constituted insanity; that a man might be insane and recover perfectly ; that a combined suicidal and homicidal attack might be of short duration, and might be perfectly recovered from; that the ideas he had expressed as to the special connection between consumption and insanity were his own, and though admitted now by many eminent men, were not universally accepted. He said that no doubt a medical man in attendance had the best chance of seeing a patient's mental state, but he might not be thinking of this aspect of his patient, and might not have all the facts before him on which to found a conclusion. Dr. Clouston's evidence was specially commended by the President for its clearness and fairness. Mr. Page concurred generally with Dr. Clouston in his evidence.

Dr. Sutherland had previously instructed the counsel for the defendants in the line they were to take medically, and Dr. Bucknill instructed counsel for the plaintiffs.

The President summed up the case to the jury, dwelling strongly on the facts that the medical men had stated that the insanity was not incurable-that suicidal mania was frequently due to sudden impulse, and that though a man might labour under it for a considerable period, he might at the same time be of sound mind; that the letters of the testator showed that he was a man of superior intellectual power down to a very recent period of his life, and that there were no real delusions on the part of the deceased. He also dwelt on the fact that he had never been treated by any one during his life as being insane.

The jury retired, and after deliberating for a few minutes, found a verdict for the plaintiffs on all the issues.

The Court pronounced for the will, costs to follow the event in the case of the defendants, but the intervener not to be condemned in costs.

\title{
Correspondence.
}

\section{ILLUSIONARY AND FRAUDULENT ASPECTS OF SPIRITUALISM.}

\author{
Second Letter from Mr. Stuart C. Cumberland.
}

\section{To the Editors of the "Journal of Mental Science."}

Gentlemen,-Dr. Edmunds demonstrated the fact before the Sub-Committee of the Dialectical Society formed to meet Mr. Home, that heavy though the table used by them was it could, with the slightest muscular exertion, be very readily oscillated. There is nothing, therefore, very extraordinary in several people standing round a table, thoroughly impressed with the idea that eventually it will rise, to unconsciously clutch the edge of it and lift it up themselves, imagining the whole of the time that they have had no hand in what, to their mind, is a positive instance of "spirit" or "psychic" power. With a confederate a medinm may easily, without risk of detection, canse a good-sized table to be raised several feet from the ground. It may be, and is often done in this fashion:-Round the medium and his confederate's wrists are clasped flat fine steel bracelets, and sliding between the inside of each bracelet and the flesh is a long blade of steel or iron. All this is hid by the coat sleeves, and when the medium and his confederate take their places at the table opposite each other the secreted machinery is quite indiscernible. 
All hands being placed on the table round which the company is seated, a sign from spirit-land is anxiously awaited. It speedily comes in the shape of certain vibrations, possibly caused by the unconscious physical action of the sitters, during which the medium and assistant contrive to let the steel blades slip underneath the rim of the table. Now is the time, and the medium declares that he feels the table making an upward movement : at this all rise with their hands still lying flat on the surface of the table, and with them of course rises the table so nicely balanced on the isupporting steel blades. The contention of the spiritualists is that the table is drawn upwards by the invisible agency at work, and that the sitters simply follow it; they therefore only look above the table and never beneath it, when that article of furniture takes its aërial flight. Did they but look underneath, whether it was the sitters unconsciously lifting it or the medium deftly manipulating it in the manner described, the means would be apparent. But spiritualists seem utterly blind to trickery-conscious or unconscions.

Then we hear of heavy tables being raised and smashed to pieces on the ground by invisible power. But, I ask, what would be easier when the table is so raised to let it fall suddenly, and would not its own weight be sufficient to smash it after orthodox spiritualistic fashion?

When I see a table rise in the air without anyone touching it, and when the employment of wire, or some machinery of a similar character for raising it is out of the question, I shall be inclined to think there is something in such a manifestation beyond mere trickery and illusion.

Table-Turning, which at one time was so important a featare of Spiritualism, has now almost entirely disappeared from the list of manifestations provided by the mediumistic fraternity for the especial delectation of the credu. lous believers in the "occult." It is not now as in Faraday's time, when, as he said, hundreds of tables were nightly tarning in the metropolis; for I question if there can now be found one professional medium in London who gives table-turning séances. Professor Faraday did much to expose the delusion of the affair, and Dr. Carpenter has since considerably aided in exploding what at best was but a pitiable self-deception. How anyone could for an instant have imagined that the "spirits"-good or evil-had anything to do with the eccentric movements of tables, unconsciously or consciously manipulated by the operators themselves, passes all belief. Let a number of persons seat themselves round a table, and place their hands upon it with a preconceived idea that the table will turn, and for a certainty under the unconscious muscular action of the sitters, it will do so. The indicator invented by Professor Faraday conclusively proved the existence of this muscular action, which entirely accounted for table-turning manifestations. If, as the believers aver, they use neither consciously nor unconsciously any pressare upon the table during the turning manifestations, why doesn't a table turn by itself in their presence without any sort of contact with them ?

By smearing oil upon the surface of the table, "turning manifestations" are at once stayed. The medium's hands have thus no grip on the table, which refuses to act, proving beyond all reasonable doubt that without the exertion of muscular action by the operator himself, "the spirits" decline to manifest their presence.

'TABLE 'Iliting is explained on the same hypothesis. A medium places his hands upon a table which, whilst influenced by "the spirits" answers questions put to it by tilting.

This tilting, if the medium be honest, is undoubtedly caused by the unconscious muscular action (whilst with a professional the action would be a conscious one of the operator) and the answers thus given reflect for a certainty his or her mental state. Dr. Carpenter, in the Quarterly Review for October, 1871, has exhaustively dealt with this parlicular phase of Spiritualism: and there is really little left for one to say upon the matter. One's personal experience 
entirely goes towards corroborating the views advanced by this eminent physiologist, and is of itself convincing that the Unconscious Muscular Action theory was not one expressly invented by scientists opposed to Spiritualism for the occasion.

The following incident is expressly illustrative of this :-

Some time back I received a requisition to attend a séance where genuine manifestations were to be witnessed. I accepted the invitation, and only put in an appearance in company with a young friend at the appointed hour. The séance, which consisted of table-tipping manifestations, opened with prayer. But though we waited patiently for some time, no "spirits" manifested their presence. The patriarch of the circle explained that it was just possible the "spirits" were offended at my presence, I being such a determined foe of spiritualism; and that in inviting me without having first asked the consent of their angel guardians, they had taken upon themselves a grave responsibility. My reply was that I came as an honest investigator, willing to be convinced if the proof were forthcoming. But still no manifestations were produced, the table remaining perfectly stationary.

I then asked if there was any sceptical influence at work which prevented "the spirits" manifesting; and, just as I expected, under the action of the sitters' hands, the table tipped the answer Yes (three tips). I then asked if I were the sceptic, and once more the table tipped an answer in the affirmative.

In putting the next question whether there would be any manifestations or not, I knew I should get a convincing proof of the agency to which the movements of the table were really due. For, in glancing hastily at the faces of the sitters, after putting the question, I discovered that they were in no way agreed upon this point. The sitter on my left wore the determined look of "no manifestations," whilst the next to him had uncertainty written on his face, and the second from him seemed equally uncertain, whilst the one on my right seemed to convey the impression that there would be some manifestations; on the part of myself and friend we were perfectly passive agents. Under this conflicting mental state of the sitters, the table began to waver in a state of uncertainty, until those who were in favour of no manifestations got the upper hand, and, in consequence, the table tipped once, meaning No. " Then there will," I replied, " be no manifestations," and in an instant I held my thumb under the rim of the table. I saw the sitters exchange glances, and once more the table began to waver, finally under the predominating influence of those who were in favour of "the spirits" manifesting, it tipped out an answer negativing the first. With my thumbs thus placed, I distinctly felt the sitters opposite to me push the table, causing it to tilt.

I there and then explained what I had done, and the sitters were unable to reply to what must have been absolutely convincing that they and they alone caused the table to move. I believe, so far as I was able to judge, that these persons were perfectly honest thongh self-deluded. For years they had been sitting at this table, unconsciously causing it to turn, fally believing that the action was due to "spirits." So convinced were they of the genuineness of the affair, that they had expressly invited me for the purpose of showing me that there were some manifestations due to spiritual agency.

In all instances of table-turning and table-talking which I have investigated, I have either found professional trickery or unconscious self-deception the instruments causing the manifestations. It is refreshing to learn that this view is rapidly becoming general, and that, in a very short time, very few indeed will be found to believe that the eccentricities of tables are caused other than by perfectly natural means.

TABLF-RAPPING was the first phase of spirit manifestation introduced in connection with Modern Spiritualism. We all, I presume, know how, in the spring of 1848, the light of the New Dispensation dawned at Hydesville, near Rochester County, N.Y.; and how from very small beginnings this most unequi- 
vocally degrading of all Epidemic Delusions rapidly spread over the old world and the new, nntil it assumed its recent gigantic proportions. Two little girls named Margaret and Katherine Fox were the first mediums, and it was through their mediamship that spirit-rapping manifestations were originally heard. Both these mediums, who cansed intense excitement throughout the United States, eventually settled in England. Katherine, in 1852, married Mr. Henry Jencken, barrister-at-law, a well-known spiritualist, whilst her sister Margaret was led to the altar by Dr. Kane, the Arctic explorer, and has been left his widow.

It was not, however, either of those gifted beings who familiarized us in England with table-rapping séances. Another famous medium, Mrs. Haydon, an American, first introdaced professional Spiritualism into London in 1853, some two years before the arrival of the celebrated D. D. Home. Her séances were much frequented, and she seems to have thriven remarkably well upon the credulity of superstitious Britishers.

The modus operandi of one spirit-rapper is like that of another. The Foxes, the Marshalls, Home, Mrs. Haydon, and other famous mediums, undoubtedly produced their raps through the displacement of their joints.

Excellent raps may be produced by snapping the big toe, with the foot resting upon the floor, the wood acting as a sounding board. Another method is the elbow pressing against the table or wainscotting, to displace two of the knuckles, and as the tendons slide back into their sheaths, raps lond and distinct can readily be heard. The same effect may be obtained by halfdislocating the knee; whilst a very favourite method, with the mediumistic fraternity, is to displace the tendon of the peroneus longus muscle, in the sheath in which it slides behind the external malleolus, by which means some very formidable rapping sounds may be produced. Dr. Schiff, of Frankfort, once gave a demonstration of his powers of imitating the spirit-rappers in this way, and a few others whom I have witnessed, have produced similar effects.

All this, of course, requires a great deal of practice, and, like the Fox girls,* I have, for my own part, found that soaking the limbs in hot water greatly facilitates the production of raps. When the feet and hands are cold or chilled it is extremely difficult to produce any sound.

The chief merit of this nice little arrangement lies in the fact that the risk of discovery is infinitely small. A medium, generally a female, takes her seat at a table, her feet being hidden by her dress. "Are there any spirits present ?" will probably be the first question put, and the spirits will signify their presence by rappingt three times upon the table. Now it is impossible, under these conditions, to have seen the medium click her toe or displace the peroneus longus, and the investigators, who are carefully watching every movement of the medium's body, are naturally inclined to believe that she takes no part in producing the raps.

I often hear very extraordinary information having been given to enquirers by spirits by means of raps. For instance, a sceptic, in every way unknown to the mediam, visits a séance, and, on the alphabet being called for, commences to run his fingers down the letters, "the spirit" rapping when the letters, forming his name, have been reached. This serves to mystify him, and he is further puzzled when "the spirit" answers, as often correctly as not, questions put by him to it. Bat there is nothing very wonderful in all this ; and I am in a position to offer a very ready explanation of this apparent marvel.

Keen women, like Mrs. Haydon and Mrs. Marshall, possessed of remarkably

* A Mrs. Culver, of Arcadia, a relative of the Fox girls, made a written confession in 1871 , setting forth how these mediums produced spirit raps by the displacement of their joints.

$t$ One rap means $N_{0}$; two raps, Don't know, or Doubtful; three raps, Yes; whilst five signify that the alphabet is called for. 
quick perceptive faculties, divined their information from carefully watching the countenance of the sitter who was putting the question. If the sitter is at all emotional he will quite unconsciously, in nine times out of ten, betray, by facial expression, when the right letters have been reached; and, by the same means, guide the medium in her decisions as to whether the replies to the questions put should be in the negative or affirmative. Of course, with unemotional men, the medium is liable not only to make frequent mistakes, but to be altogether afield, provided he gives her, neither by expression nor sign, any clue to the information desired. One can easily lead a medium astray by purposely pausing at the wrong letters; at every pause you make-apparently unconsciously - the "dear spirit" will rap in the affirmative. You may thus get "the spirits" to spell out "Jones," when the correct name should be "Robinson." If you yourself don't remember a name or date "the spirits" will exhibit the same indecision in their replies, showing that they are guided by the outward expression of correctness or incorrectness that you afford them. All this faint reading by mediums is undoubtedly very clever, but it is really very remarkable how difficult it is with some people, under the influence of expectant attention, to control their muscles so as to offer no clue as to what is going on in their minds. With such people, keen-sighted mediums, with their natural perceptive abilities sharpened by practice, have an easy task; but with less impressionable persons a greater difficalty is experienced, whilst, as I have pointed out, nothing but failure results from those possessing a stoical temperament.

I have already stated how difficult it is to tell where sonnd really comes from. When Home was sitting with the Committee of the Dialectical Society, it will be remembered that, beyond a few puny raps and slight movements of the table, no manifestations of any importance were produced. Indeed, the only interesting part of the proceedings was the diversity of opinion, which existed at the time amongst the members of the Committee, as to the direction from which the raps really came.

Mr. Charles Bradlaugh and Mr. Dyte were thoronghly convinced that the raps came from the leg of the table, whilst Lord Lindsay (the Earl of Crawford), and other friends of the medium, were equally positive that the raps came from the top of the table. The two former members were, however, quite unconvinced, and Mr. Bradlangh squatted on the floor, watching the table leg without, however, discovering the secret.

It is a well-known fact, that if the attention of the sitters is drawn towards the table top, from which spot they expect the raps to come, and the medium raps at the foot of the table, they will, in all probability, unanimously decide that the sounds came, not from the place where they were made, but from the spot upon which they had fixed their gaze. One cannot see a rap, and, therefore, one has to trast entirely to one's 'sense of sound, which is ever deceptive. In the confession of Mrs. Culver, before alluded to, some interesting disclosures are made with respect to the manner in which the Fox girls deceived the sitters in the matter of sound.

Sometimes a professional medium, when he has established himself in a certain spot, has electro-magnets fitted up in his séance room, by means of which he is able to produce raps far louder and more distinct than can ever be expected to come out of the displacement of the joints. I have tried this method with considerable success; but there is this objection to it, which the spiritualists likewise recognise: the electrical apparatus is liable to get out of order, and therefore to fail at any moment, whilst the risk of discovery is considerable. On the other hand, the displacement of the joints is ever found to be a reliable, and not easily discovered method, of calling up the "spirits from the vasty deep."

Spirit-rapping, like table-turning, has, however, seen its day, and, with the exception of an occasional séance, given by Mrs. Kane or Mrs. Marshall, those 
rapping exhibitions which were so popular in the palmiest days of D. D. Home have disappeared from the répertoire of spiritualistic tricks. I need hardly, in conclusion, add that there are various other mechanical means-which it would be superfluous to enumerate-by which "spirit raps" may be produced, but I have confined myself to explaining only those methods chiefly adopted by the best known rapping mediums.

Materializations are considered by the faithful the acme of "spirit manifestations." By the theory of materialization the subjective ghosts of the memory are entirely supplanted by objective forms, who are able to eat, drink, and be merry after the fashion of mortals. This particular phase of manifestation did not present itself at the commencement of the movement, and it was only when the American public was sufficiently "educated" by the prophets of spiritualism to accept such perfection of imposture that so-called "materializing mediums" came to the front. At first only hands, feet, fingers and toes, or perhaps a head and face, were materialized, but a credulous public ever eager for new marvels, cried out for fall forms, and full forms they accordingly had. I think it hardly necessary to say that there is not one genuine instance of materialization on record. It is to insult one's common sense to ask one to believe that those who depart this life would leave the presence of our Heavenly Father at the beck and call of any ignorant impostor, who feels himself especially qualified for the task to strut about séance rooms in earthly shape and in earthly attire for the enrichment of rascals and the wonderment of fools.

There is hardly one so-called materializing medium who has not at some time or other been exposed, and the instances where these nefarious practitioners have been caught in the act of personating spirit forms have been very numerous. The most notable exposures are those of Egerton, of "Jack Tod" notoriety, and Herne as "John King," at Liverpool ; Sir George Sitwell's capture of Mrs. Corner (who was so warmly endorsed by Professor Crookes), whilst personating the "spirit Marie," and my exposure last August of the notorious Bastian whom I squirted in the eye with liquid cochineal whilst manifesting as an alleged spirit brother of mine, thus proving conclusively that the medium and the spirit were one and the same person. About this time a Mrs. Esperance was also seized at Newcastle whilst appearing as an Indian spirit " Yolandi."

I have no hesitation in saying that every materialization is due to trickery. Every objective form hailing from "spirit land" that manifests itself is undoubtedly either the medium or a confederate suitably attired for the occasion. T'rue it is that "spirit forms" may be produced by mirrors and lenses, but their application is awkward and but rarely resorted to.

The methods of materializing "spirits" are infinite, and were I to give you in detail the numerous little artifices resorted to by professional media in producing the manifestations, very many pages beyond what this letter itself will occupy, would be required to contain a notice of them. I will therefore confine $\mathrm{n}$ yself to explaining the methods principally employed.

At many séances no tests are demanded, and all that the medium has in such cases to do is to retire behind the curtains of the cabinet and deck himself out in appropriate spirit garments carried about his person. Whilst influenced by expectant attention, many feebleminded sitters will not fail to recognise in the grotesquely attired person of the medium an exact likeness of some dear lost one.

At some séances, however, "tests" are employed which the medium invariably manages to evade. Before entering the cabinet the medium, we will say, is searched by some sceptical person present, nothing being found on him. Yet, soon after he has entered the cabinet a "spirit form" emerges from it attired in spiritual raiments. This is very puzzling, and even the sceptics who undertook the search are fain to express their astonishment. There can, how- 
ever, be no doubt but that the medium has either secreted the garments with which "the spirit" was attired about his person or in some part of the cabinet. In the former case, a necktie may contain a yard or so of muslin, in the hollow bottoms of his shoes may be secreted further garments, as the hollows of his arms are used to secret fine india-rubber masks, or what not. A false lining in his coat serves to contain an entire spirit dress, the threads being so arranged that he can readily manipulate the secret pocket. You also may have possibly noticed that prior to the commencement of the séance the medinm, under some pretext or other, enters the cabinet, and that he will afterwards express his readiness to undergo a search. His entering the cabinet excites at the time no suspicion, but in that moment he has hurriedly slipped underneath the seat of the sofa apon which he is to recline the material with which the spirits are to be built up. Another method is for a confederate, under the pretext of seeing if the medium is in a trance, to pass spirit garments to him between the curtains. Many materializing mediums are of the gentler sex, and, as may be readily imagined, their dresses afford no end of facilities for the secretion of spiritual trappings. A well known medium confessed to the late Sergeant Cox that she used to hide a spirit dress in her drawers. No wonder then that a search was invariably ineffectual. Chignons, too, were very handy for secreting things.

Sometimes mediums are tied as a test; but every one knows how a street itinerant can release himself from the most intricate bonds, and for a medium to get loose from ropes far less tightly tied is by no means difficult.

All this tying and binding are in themselves elements of suspicion. If " the spirits" could come at all, they would, I venture to think, come quite as well with the medinm free in full sight of the audience as when he is tied, shut up in a cage, placed in a bag, or with a net drawn over him. Neither of these ignoble tests is calculated to increase the respect of the spirits nor to further that indescribable power said to be necessary for the production of these and kindred manifestations.

At séances where a medium is permanently established, a trap door is nearly always let into the floor through which "visitors from the other world" in the shape of hired supernumeraries can appear. In such case the medium and the spirits-a grand proof in the eyes of the faithful-can be seen together. These credulous dupes never seem to dream of confederates.

One often hears wonderfal accounts of materializations in private houses; but in all those cases no "tests" of any kind appear to have been imposed, and the medium is allowed to take his own time to produce his spirits, whether himself bedecked in muslin, or inflated skin figures skilfully manipulated by lazy tongs. Of course there is trickery in all such manifestations, and the only wonderfal thing about the matter is that the sitters fail to discover wherein the trick lies.

But the simple fact is, those who habitually attend spirit séances are very readily deceived. In their eyes, a dirty piece of muslin is a fabric of wonderful beanty, a painted mask is a face of ethereal loveliness, whilst a vulgar medium waddling about the chamber in newspaper leggings and John King whiskers is a "noble being with a fine commanding presence." Such people never seem to look at the common-sense side of the matter. In their eyes everything is real, everything beautiful, and absolutely without guile.

To persons with minds so peculiarly constituted there is perhaps no reply; they are wedded to their idols, and, as Professor Tyndall once remarked to me, one might as well attempt to place a new core in a rotten apple as put new hearts into persons so peculiarly diseased. There are others, however, who are open to conviction, and it is to these, and to those who have not yet commenced an investigation into spiritualism, that I here address myself. 
Spiritualism is a question of evidence and evidence alone, and I have, I trust, clearly demonstrated the value of some of the evidence brought forward by spiritualists as affording indubitable proof of the Immortality of the Soul. I have shown that half the manifestations are the result of trickery, whilst an equal number may be placed to the credit of self-deception. Space forbids me at the present time going further into the subject, but on a future occasion it will afford me much pleasure to place before your readers further explanations of the methods employed by so-called mediums in imposing upon the senses and in corrupting the morals of their dupes.

In conclusion, I can only trust that my letters may be productive of good results.

Believe me to be, Your obedient servant,

May, 1881. STUART C. CUMBERLAND.

\section{Obituary.}

\section{DR. BREWER.}

Dr. Brewer, the respected Chairman of the Metropolitan Asylum Board, died, greatly regretted, at his residence, George Street, Hanover Square, on the 3rd of November, 1881. He occupied this post from the time the Board was formed. He was the Liberal M.P. for Chelmsford from 1868 to 1874 . He was a Fellow of the Royal College of Physicians, and graduated at St. Andrews in 1834. He threw his whole mind into the work of the Metropolitan Board, and laboured unceasingly and conscientiously at the oar till his death from angina pectoris.

"From the beginning to the end he worked from the pure love of the work and for the great object he had at heart, without seeking or receiving any sort of remuneration for his services."-British Medical Journal.

Dr. Brewer was also Chairman of the Sanitary Committee of the Metropo. litan Board of Works.

\section{JOSEPH J. BROWN, M.B., F.R.C.P.E.}

In the death of Dr. Joseph John Brown our Association has lost one of the most promising of its younger members. Dr. Brown was the son of the late Dr. J. Brown, of Wooler, and studied at Edinburgh University, where he earned high distinction as a stadent, and graduated with honours in 1871 . After acting for some time as Resident Physician for the University Clinical Wards and the Fever Wards of the Edinburgh Royal Infirmary, he became Assistant Physician at Saughton Hall Asylum, and, under the guidance of Dr. J. Batty Tuke, devoted himself with characteristic energy to the study of the microscopical appearances of the brain in insanity. In 1874 he was appointed one of the Assistant Physicians in the Royal Edinburgh Asylum. His success here was so marked that when in 1878 the office of Medical Superintendent of the Fife and Kinross District Asylum became vacant, Dr. Brown was without competition unanimously appointed to it.

To natural abilities and professional acquirements of a very high order Dr. Brown added qualities of head and heart which eminently fitted him for the special work to which he devoted himself. He had great administrative 